\title{
Ablation Therapy as Management of Typical Atrial Flutter in the Early Period After Cardiac Surgery
}

Leon Iden · Susann Groschke - Rolf Weinert • Ralf Toelg •

Gert Richardt $\cdot$ Martin Borlich

Received: February 25, 2021 / Published online: May 24, 2021

(C) The Author(s) 2021

\section{ABSTRACT}

Introduction: Available data on management of atrial flutter in the early postoperative setting after cardiac surgery are scarce. We aimed to investigate the safety and efficacy (profile) of flutter ablation in the early postoperative phase (30 days after cardiac surgery) in a cohort of 47 consecutive patients.

Methods: Between 2007 and 2016, 47 patients who underwent ablation for postoperative typical atrial flutter were retrospectively identified and analyzed. Follow-up data were acquired from patients' records in case of rehospitalization and via follow-up calls.

Results: The median age of patients was 69 years, $89 \%$ male and with a median LV-EF of $55 \%$. CAD was present in $80.8 \%$ of patients. The predominant conduction of atrial flutter was $2: 1$ (76.6\%); $85.1 \%$ of patients had either undergone CABG, SAVR, or a combination of these two. Acute procedural success could be achieved in $100 \%$ of patients with one vascular pseudoaneurysm that was managed conservatively. No other complications occurred. After a median follow-up of 5.7 years, follow-up information

L. Iden $(\bowtie) \cdot$ S. Groschke · R. Weinert · R. Toelg . G. Richardt · M. Borlich

Department of Cardiology, Herzzentrum Segeberger Kliniken GmbH, Am Kurpark 1, 23795 Bad Segeberg, Schleswig-Holstein, Germany

e-mail: leon.iden@segebergerkliniken.de regarding heart rhythm was available in $87.2 \%$ of patients. One patient $(2.1 \%)$ had undergone repeat ablation for typical flutter. Two patients (4.2\%) had developed atrial fibrillation, while $87.2 \%$ of patients were in sinus rhythm.

Conclusions: In this small cohort, early postoperative ablation of typical flutter was associated with a favorable short- and long-term safety and efficacy profile and can be considered part of heart rhythm management options in this setting.

Keywords: Postoperative arrhythmia; Atrial flutter; Ablation; Postoperative management

\section{Key Summary Points}

Why carry out the study?

Postoperative supraventricular arrhythmias contribute to adverse outcome after cardiac surgery.

Typical atrial flutter can be found as an isolated or predominant arrhythmia and has not been studied in this setting.

What was learned from the study?

Ablation therapy within 30 days after cardiac surgery was safe and effective in a cohort of 47 patients studied.

During long-term follow-up, few patients developed atrial fibrillation. 


\section{DIGITAL FEATURES}

This article is published with digital features, including a summary slide, to facilitate understanding of the article. To view digital features for this article go to https://doi.org/10.6084/ m9.figshare.14555310.

\section{INTRODUCTION}

Typical atrial flutter is a well-understood arrhythmia resulting from a right atrial macroreentrant circuit. Due to the involvement of anatomic structures forming either functional barriers of conduction or even being nonconductive structures, the arrhythmia is usually found to be very stable and not prone to spontaneous termination [1].

Ablation of the arrhythmia is associated with a high long-term success rate and low overall complication rate. Therefore, it is an acceptable first-line treatment [2].

Postoperative supraventricular arrhythmias are common after cardiac surgery associated with multiple adverse findings regarding outcome, costs, prolonged hospitalization, complications and reoperation. The most commonly found arrhythmia is atrial fibrillation $[3,4]$. Atrial flutter is found less commonly after cardiac surgery where it can occur as an isolated or predominant arrhythmia [5]. Whereas in postoperative atrial fibrillation, triggering and maintenance of the arrhythmia is influenced by multiple conditions related to surgery like fluid imbalances, inflammation, sympathetic activation and electrolyte shift, typical postoperative atrial flutter exhibits the same flutter circuit as in a non-postoperative setting [6, 7]. Management strategies are usually adopted from atrial fibrillation patients, however few data exist on dedicated management of atrial flutter in this setting [8]. Conventional management options include electrical or pharmacological cardioversion, rate control, or antiarrhythmic drug therapy. In part, due to the anatomically fixed structures contributing to the reentrant circuit, typical atrial flutter has a considerable recurrence rate when managed conservatively [9].

There have been multiple publications on the ablation of cavotricuspid isthmus-dependent arrhythmias with or without targeting additional substrate in the right atrium late after cardiac surgery (i.e., "incisional flutter"), however, to the best of our knowledge, ablation therapy as a management option for typical flutter early after cardiac surgery has not been previously described [10].

We aimed to assess the safety and feasibility of ablation therapy as a management option of typical atrial flutter in the early postoperative period 30 days after cardiac surgery.

\section{METHODS}

In this retrospective, single-center analysis, patients who underwent ablation for typical flutter within the first 30 days after cardiac surgery between 2007 and 2016 were assessed. Surgical procedures not requiring access to the pericardium (i.e., laser-guided lead extraction) were excluded.

Follow-up information was obtained from electronic patients' records in case of rehospitalization in our institution and via phone calls. The patients were analyzed for cardiac status, recurrence of arrhythmias, and cardioversions.

The registry was approved by the local ethics committee of the Aerztekammer SchleswigHostein under reference 168/11 I and conforming to the Declaration of Helsinki of 1964 and its later amendments, and each patient has provided a written informed consent for analysis of anonymized data.

All patients who underwent ablation were included in the safety analysis regarding procedural complications and vital status at discharge.

Patients with available rhythm status were included into the efficacy analysis for long-term rhythm outcome (Fig. 1). 


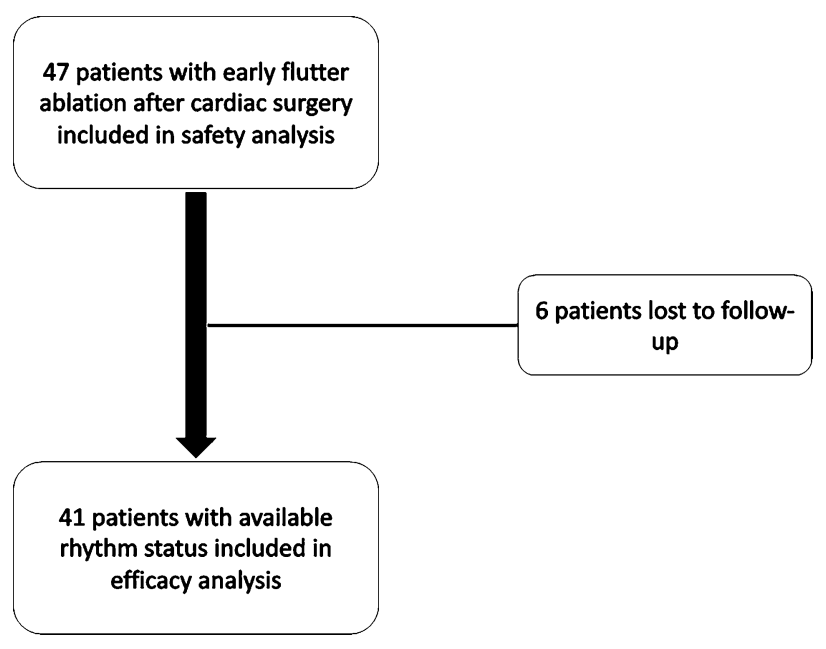

Fig. 1 Patient populations analyzed

\section{RESULTS}

Between 2007 and 2016, 47 patients underwent ablation for typical flutter within the first 30 days after cardiac surgery. Patient characteristics are shown below (Table 1).

Thirty-five patients (74\%) had at least one failed attempt of non-invasive treatment (i.e., electrical or pharmacological cardioversion or rate control).

Eight patients (17.1\%) had pre-existing atrial fibrillation and two patients (4.2\%) had preexisting atrial flutter. No patients had had surgical ablation procedures.

Surgical procedures are shown below (Fig. 2). Forty patients $(85.1 \%)$ had undergone either CABG, SAVR, or a combination of these two. Five patients $(10.6 \%)$ had procedures requiring atriotomy.

Ablation procedures were performed with 3D electroanatomical mapping in three patients $(6.3 \%)$. All other procedures were performed under utilization of fluoroscopy guiding. Thirtyone patients $(65.9 \%)$ underwent ablation with a three-catheter setup (coronary sinus catheter, ablation catheter, and 20-polar mapping catheter along the tricuspid anulus), 16 patients $(34.1 \%)$ with a two-catheter setup (coronary sinus catheter and ablation catheter) requiring triple and double femoral venous access, respectively. No arterial access was used. Fortytwo patients (89.3\%) underwent ablation under ongoing tachycardia, while five patients $(10.7 \%)$ were in sinus rhythm. In case of ongoing tachycardia, typical flutter was confirmed by entrainment maneuvers. In case of sinus rhythm, ablation of the cavotricuspid isthmus was performed during pacing from the proximal coronary sinus. No additional ablation lesions besides the cavotricuspid isthmus line were performed.

Two patients underwent an EP study for suspected typical flutter but were diagnosed with left atrial flutter. These patients are not included in this analysis.

Acute procedural success defined as bidirectional block of the cavotricuspid isthmus line could be achieved in 100\% of patients.

In one patient, a femoral venous pseudoaneurysm with subsequent conservative management occurred. Besides this, no further complications of the ablation procedure were noted. At the time of discharge, 45 patients $(95.7 \%)$ were in sinus rhythm, while two patients $(4.2 \%)$ had developed atrial fibrillation.

During the first 8 weeks following flutter ablation, three patients $(6.3 \%)$ had temporary interruption of anticoagulation, one patient in the context of vascular pseudoaneurysm after ablation, and two patients in the context of pleural puncture. Besides the aforementioned vascular pseudoaneurysm, no major bleeding (BARC III-V) or thromboembolic complications were noted. 
Table 1 Baseline patient characteristics

\begin{tabular}{|c|c|}
\hline & Patients with early postoperative ablation, $n=47$ \\
\hline Age [years], median $\pm \mathrm{IQR}$ & $69 \pm(63-75)$ \\
\hline Male sex $n ;[\%]$ & $42(89.4)$ \\
\hline LV-EF $[\%]$, median $\pm \mathrm{IQR}$ & $55.0 \pm(45-55)$ \\
\hline LV-EF $<35 \%$ & $6(12.8)$ \\
\hline CAD $n ;[\%]$ & $38(80.8)$ \\
\hline Prior PCI $n$; [\%] & $8(17.0)$ \\
\hline Pacemaker $n ;[\%]$ & $5(10.6)$ \\
\hline ICD $n ;[\%]$ & $1(2.1)$ \\
\hline \multicolumn{2}{|l|}{ Conduction } \\
\hline $2: 1 n ;[\%]$ & $36(76.6)$ \\
\hline $3: 1 n ;[\%]$ & $6(12.8)$ \\
\hline$>3: 1 n ;[\%]$ & $5(10.6)$ \\
\hline CABG $n ;[\%]$ & $34(72.3)$ \\
\hline SAVR $n ;[\%]$ & $17(36.2)$ \\
\hline Mitral valve repair $n ;[\%]$ & $3(6.4)$ \\
\hline Mitral valve replacement $n$; [\%] & $1(2.1)$ \\
\hline Other surgery $n ;[\%]$ & $3(6.4)$ \\
\hline Combined interventions $n$; [\%] & $11(23.4)$ \\
\hline
\end{tabular}

At discharge, nine patients (19.1\%) were treated with amiodarone. One patient (2.1\%) had been started on amiodarone after the ablation while the remaining eight (17.1\%) patients were kept on amiodarone therapy initiated before the ablation.

At a median follow-up of 5.7 years, follow-up information regarding heart rhythm status was available in 41 patients (87.2\%). Thirty-eight patients $(92.7 \%)$ were in sinus rhythm. Two patients $(4.8 \%)$ had developed atrial fibrillation. One patient $(2.1 \%)$ had undergone repeat ablation for atrial flutter with consecutive sinus rhythm. Three patients (6.3\%) had died; two of cardiac causes (endocarditis/myocardial infarction) and one of a non-cardiac cause (lung cancer).

Follow-up information on antiarrhythmic drug therapy was available in 30 patients
(73.2\%). Two patients were treated with amiodarone. No other Class I or III antiarrhythmic drugs were used.

\section{DISCUSSION}

In this small patient cohort, ablation of typical atrial flutter in the early postoperative phase was associated with a favorable safety profile and long-term rhythm outcome.

Safety and efficacy seem to be comparable to patient populations treated outside the acute postoperative setting after cardiac surgery $[10,11]$. Long-term efficacy does not seem to be associated with long-term antiarrhythmic drug therapy.

The necessity of continued anticoagulation after ablation is a special concern in the early 


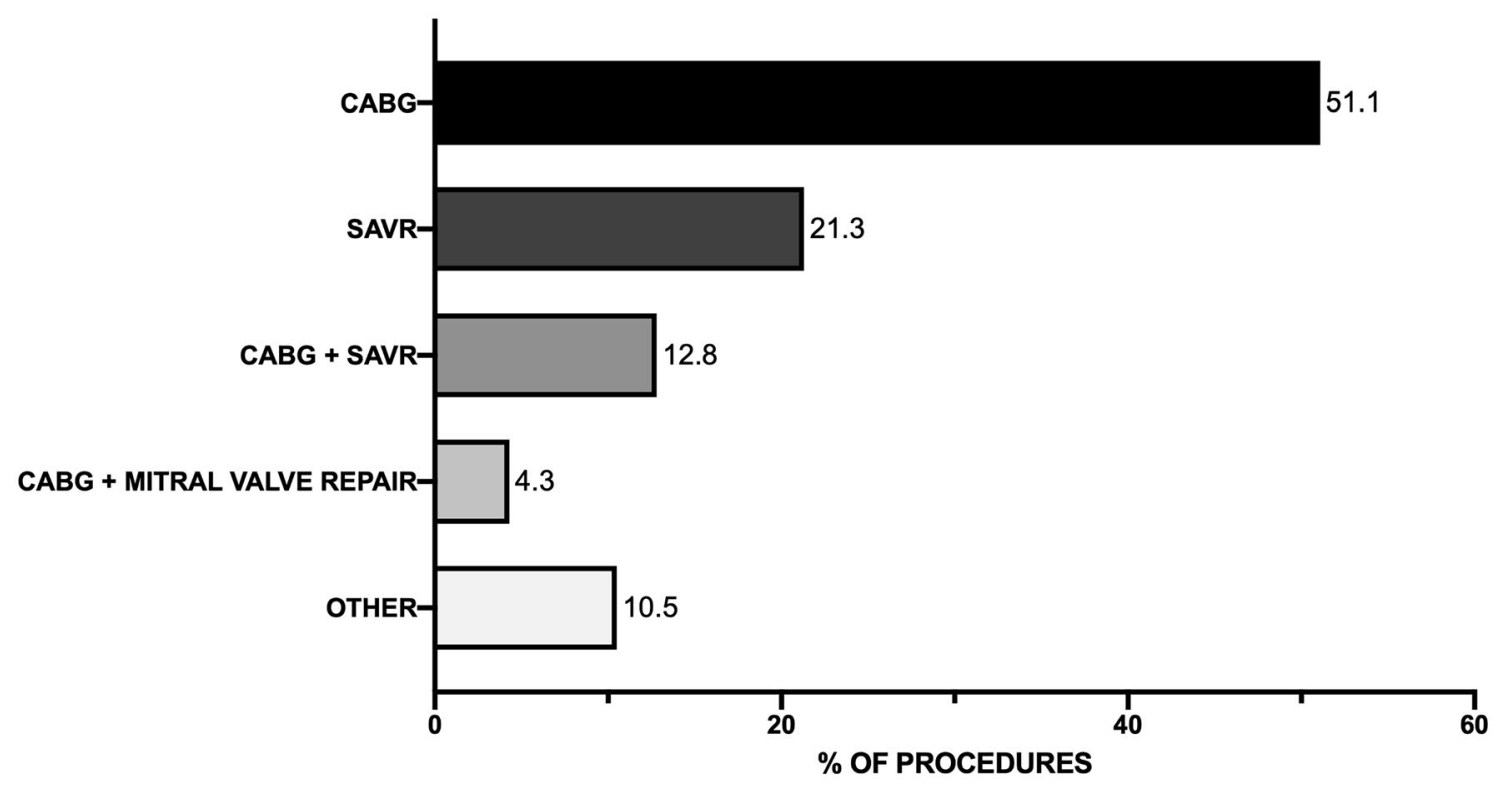

Fig. 2 Types of operations

postoperative setting. In this cohort, pausing of anticoagulation was only necessary in a small proportion of patients without clinical impact. Further, other rhythm-control strategies like cardioversion also mandate continued anticoagulation due to stunning of the left-atrial appendage.

Of note, only a small subset of patients developed clinically detected atrial fibrillation during a median follow-up of 5.7 years. This finding is contrary to other long-term studies that report higher incidences of atrial fibrillation [9-12]. Presumably, the development of atrial flutter as the sole or predominant arrhythmia shortly after cardiac surgery can be interpreted as an event with low susceptibility towards atrial fibrillation, which is usually the much more commonly observed arrhythmia in the postoperative setting. This effect seems to prevail over the follow-up period. This observation may play a role in the decision on longterm anticoagulation strategies.

There are important limitations to this study. Most importantly the number of patients is limited. Also the study is of retrospective nature without predefined endpoints. Further, we have no meaningful data available on patients with postoperative flutter and conservative management, especially regarding long-term rhythm outcome.

Therefore, these findings should be validated within larger patient populations, ideally within a randomized approach against strictly conservative management.

\section{CONCLUSIONS}

Ablation of typical atrial flutter was associated with favorable outcomes and safety profile in this cohort and can be considered an option for interdisciplinary rhythm management in these patients. Due to the limitations of this study, the approach should be validated in larger cohorts before being implemented into routine practice.

\section{ACKNOWLEDGEMENTS}

Funding. No funding or sponsorship was received for this study or publication of this article.

Authorship. All named authors meet the International Committee of Medical Journal 
Editors (ICMJE) criteria for authorship for this article, take responsibility for the integrity of the work as a whole, and have given their approval for this version to be published.

Author contributions. LI contributed by: concept and design, data acquisition, statistical analysis, drafting of the manuscript, revision and finalization of the manuscript. SG, RW and RT contributed by: revision and finalization of the manuscript. GR and $\mathrm{MB}$ contributed by: concept and design, revision and finalization of the manuscript.

Prior presentation. Part of the data without the follow-up in formation was presented as a moderated poster during the 2017 annual meeting of the German cardiac society (DGK).

Disclosures. Leon Iden has received consultant honoraria and/or lecture honoraria and/or and travel grants from: Abbott Medical, Bayer, Berlin-Chemie, Biosense Webster, Biotronik, Bristol-Myers-Squibb, Daiichi-Sankyo, Medtronic, Novartis. Susann Groschke has received travel grants from: Daiichi-Sankyo. Rolf Weinert has received travel grants and/or lecture honoraria from: Abbott, Biosense Webster, DaiichiSankyo, Medtronic, and Pfizer. Ralph Toelg has received lecture honoraria from: Biotronik. Gert Richardt has received consultant honoraria and/or lecture honoraria and/or research funding from: Abbott, Bayer, Biotronik, Boston Scientific, Edwards, Medtronic, Novartis. Martin Borlich has received consultant honoraria and/ or lecture honoraria and/or and travel grants from: Bayer, Biosense Webster, Biotronik, and Boston Scientific.

Compliance with ethics guidelines. The registry was approved by the local ethics committee of the Aerztekammer Schleswig-Hostein under reference 168/11 I and conforming to the Declaration of Helsinki of 1964 and its later amendments, and each patient has provided a written informed consent for analysis of anonymized data.
Data availability. The data derives from patients' records from out institution and is therefore not publicly available.

Open Access. This article is licensed under a Creative Commons Attribution-NonCommercial 4.0 International License, which permits any non-commercial use, sharing, adaptation, distribution and reproduction in any medium or format, as long as you give appropriate credit to the original author(s) and the source, provide a link to the Creative Commons licence, and indicate if changes were made. The images or other third party material in this article are included in the article's Creative Commons licence, unless indicated otherwise in a credit line to the material. If material is not included in the article's Creative Commons licence and your intended use is not permitted by statutory regulation or exceeds the permitted use, you will need to obtain permission directly from the copyright holder. To view a copy of this licence, visit http://creativecommons.org/licenses/by$\mathrm{nc} / 4.0 /$.

\section{REFERENCES}

1. Sawhney NS, Feld GK. Diagnosis and management of typical atrial flutter. Med Clin N Am. 2008;92(1): $65-85, x$.

2. Page RL, Joglar JA, Caldwell MA, Calkins H, Conti JB, Deal BJ, et al. 2015 ACC/AHA/HRS Guideline for the Management of Adult Patients With Supraventricular Tachycardia: a Report of the American College of Cardiology/American Heart Association Task Force on Clinical Practice Guidelines and the Heart Rhythm Society. J Am Coll Cardiol. 2016;67(13):e27-115.

3. Alqahtani AA. Atrial fibrillation post cardiac surgery trends toward management. Heart Views. 2010;11(2):57-63.

4. Greenberg JW, Lancaster TS, Schuessler RB, Melby SJ. Postoperative atrial fibrillation following cardiac surgery: a persistent complication. Eur J Cardiothorac Surg. 2017;52(4):665-72.

5. Peretto G, Durante A, Limite LR, Cianflone D. Postoperative arrhythmias after cardiac surgery: incidence, risk factors, and therapeutic management. Cardiol Res Pract. 2014;2014:615987. 
6. Funk M, Richards SB, Desjardins J, Bebon C, Wilcox $\mathrm{H}$. Incidence, timing, symptoms, and risk factors for atrial fibrillation after cardiac surgery. Am J Crit Care. 2003;12(5):424-33 (quiz 34-5).

7. Ishii Y, Schuessler RB, Gaynor SL, Yamada K, Fu AS, Boineau JP, et al. Inflammation of atrium after cardiac surgery is associated with inhomogeneity of atrial conduction and atrial fibrillation. Circulation. 2005;111(22):2881-8.

8. Frendl G, Sodickson AC, Chung MK, Waldo AL, Gersh BJ, Tisdale JE, et al. 2014 AATS guidelines for the prevention and management of perioperative atrial fibrillation and flutter for thoracic surgical procedures. J Thorac Cardiovasc Surg. 2014;148(3): e153-93.

9. Natale A, Newby KH, Pisano E, Leonelli F, Fanelli R, Potenza D, et al. Prospective randomized comparison of antiarrhythmic therapy versus first-line radiofrequency ablation in patients with atrial flutter. J Am Coll Cardiol. 2000;35(7):1898-904.

10. Verma A, Marrouche NF, Seshadri N, Schweikert RA, Bhargava M, Burkhardt JD, et al. Importance of ablating all potential right atrial flutter circuits in postcardiac surgery patients. J Am Coll Cardiol. 2004;44(2):409-14.

11. Iori M, Quartieri F, Battista A, Donateo P, Navazio A, Brignole $\mathrm{M}$, et al. Outcome of the elective or online RF ablation of typical atrial flutter. Minerva Cardioangiol. 2020. https://doi.org/10.23736/ S0026-4725.20.05380-3.

12. De Bortoli A, Shi LB, Ohm OJ, Hoff PI, Schuster P, Solheim E, et al. Incidence and clinical predictors of subsequent atrial fibrillation requiring additional ablation after cavotricuspid isthmus ablation for typical atrial flutter. Scand Cardiovasc J. 2017;51(3): 123-8. 